\title{
Carbapenamase-Producing Acinetobacter baumannii in China, Latin America and the Caribbean: A Systematic Review and Meta-Analysis
}

\author{
Haiyang Yu MD MPH, Guillermo Ezpeleta-Lobato MD MPH, Xu Han MD MPH, Yenisel Carmona-Cartaya MD MS, \\ Dianelys Quiñones-Pérez MD MS PhD
}

\begin{abstract}
INTRODUCTION Carbapenem-resistant Acinetobacter baumannii is a complex health problem, causing difficulties in clinical-therapeutic management worldwide. It is of particular concern in Latin America, the Caribbean and China, where it is an emerging health problem. Carbapenemases produced by these organisms inactivate carbapenem antibiotics. Monitoring circulating genotypes' geographic dispersion contributes to more effective control measures. However, exhaustive studies on carbapenem-resistant $A$. baumannii are scarce.
\end{abstract}

OBJECTIVES Study the production of carbapenemases in clinical isolates of $A$. baumannii resistant to carbapenem antibiotics and the geographic distribution of the sequences circulating in China, Latin America and the Caribbean.

DATA ACQUISITION We followed PRISMA indications. We carried out a systematic search in Pubmed, BVS and CKNI on papers on $A$. baumannii and carbapenemases published during 2015-2020 in English, Spanish and Chinese, and selected 29 cross-sectional studies that met the search criteria. Studies were evaluated using JBI Critical Appraisal tools, and quantitative data were collated for meta-analysis using the Metaprop library in Stata15.

\section{INTRODUCTION}

The genus Acinetobacter (Acinobacter spp.) is made up of several species. These gram-negative bacilli are among the most common nosocomial pathogens worldwide. Acinetobacter baumannil is the most clinically relevant species, due to its ability to develop various mechanisms that lend themselves to antibiotic resistance. [1] A member of the beta-lactam class (the same class of antibiotics as penicillins and cephalosporins), carbapenemic antibiotics are the last resort in treating $A$. baumannii infections.

There has been a worldwide increase in carbapenem resistance observed in clinical isolates of $A$. baumannii.[2] The Latin American Antimicrobial Resistance Surveillance Network found $A$. baumannii to have high resistance to carbapenems in 15 countries in

\section{IMPORTANCE}

This meta-analysis shows the different types of carbapenemases in A. baumannii in China, Latin America and the Caribbean, and the geographic distribution of the circulating sequence types. The data provide useful information for antibiotic resistance surveillance in the regions chosen for analysis, where this is an emerging health problem.
DEVELOPMENT OXA-type carbapenemases were detected in all studies; among $A$. baumannii resistant to carbapenem antibiotics, predominant types were OXA-23, OXA-24, OXA54 and OXA-72; metallobetalactamases were identified less frequently than OXA carbapenemases. Only one clinical isolate producer of Class A carbapenemases (KPC) was identified in Colombia. In total, 41 sequence types were identified; in Latin America and the Caribbean the most common types were: ST79, ST25, ST1 and ST15; in China, the sequences ST195, ST208, ST191, ST368 and ST369 were the most prevalent. ST2 was found in both regions.

CONCLUSIONS The most prevalent carbapenemases and sequence types vary by region, indicating different ancestral strains. Microbiological surveillance, antibiotic use optimization, adequate infection treatment and timely control strategies are essential for carbapenem-resistant $A$. baumannii prevention and control in geographies such as Latin America, the Caribbean and China where such resistance is an emerging health problem.

KEYWORDS Acinetobacter baumannii, carbapenemase, genotype, epidemiology, Latin America, Caribbean region, China

the region during 2014-2016. The percentage of resistant isolates varied from $8 \%$ to $89 \%$.[3] In China in $2016,71.4 \%$ of $A$. baumannii isolates were resistant to carbapenems.[4] WHO published a list of priority pathogens in 2017, including A. baumannii, Pseudomonas aeruginosa, and carbapenem-resistant Enterobacteriacae spp. as critical priorities.[5]

The main mechanism of carbapenem resistance in A. baumannii (CRAB) strains is carbapenemases production. The most common of these are Ambler's class D oxacillinases (OXAs). [2] Six subgroups of OXAs have been identified in A. baumannii: the species' intrinsic carbapenemase OXA-51-like, and the acquired carbapenemases OXA-23-like, OXA-24-like, OXA58-like, OXA-143-like, and OXA-235-like.[6] Class B metallobetalactamases (MBLs) are also a major threat because they are often located in mobile genetic elements, easily transferable between bacteria. Four types of MBLs are frequently detected in A. baumannii: imipenemase (IMP), Verona imipenemase (VIM), Seoul imipenemase (SIM), and New Delhi betalactamase (NDM).[7]

Molecular characterization of $A$. baumannii isolates is very useful in identifying the source of an outbreak and in helping to control its spread. Multilocus sequence typing (MLST) is highly discriminative and has been applied successfully to several bacterial patho- 
gens, including $A$. baumannii. Additionally, this typing allows for comparisons between laboratories and provides a powerful tool for conducting epidemiological studies worldwide.[8]

The emergence of carbapenem-resistant forms of $A$. baumannii is a complex global problem, difficult to manage both clinically and therapeutically. Monitoring carbapenemase genotypes and molecular epidemiology studies contribute to more effective control measures. However, comparative analyses of circulating forms in different geographies are scarce. This work is a systematic review of published information on carbapenemase production and sequence types characterized in A. baumannii isolates in China, Latin America and the Caribbean (LAC).

\section{DATA ACQUISITION}

We followed the SPIDER scheme in preparing this study.[9] We carried out a systematic review of all relevant publications in 2015-2020, adjusted according to recommendations contained in PRISMA guidelines (Preferred Reporting Items for Systematic Reviews and Meta-Analyses.)[10]

Search strategy and article selection The search was carried out in the following databases: PubMed (Medline), BVS (Regional Portal, Virtual Health Library), and CNKI (Chinese database). We used the following keyword combinations: "carbapenem resistance" OR "carbapenemase producing" combined with "Acinetobacter baumannii" combined with the names of the following countries: "Argentina", "Bahamas", "Belize", "Bolivia", "Brazil", "Chile", "China”, "Columbia”, "Costa Rica", "Cuba”, "Ecuador", "Guatemala", "Guyana”, "Haiti”, "Honduras", "Jamaica”, "Mexico", "Nicaragua", "Panama", "Paraguay", "Peru", "Salvador", "Surinam", "Trinidad", "Uruguay", and "Venezuela". We selected articles in three stages: by title, by abstract content, and finally, according to information contained in the full text.

Inclusion criteria We included studies with the following characteristics: 1) observational studies with a cross-sectional design; 2) analysis of $A$. baumannii clinical isolates in adult populations; 3 ) reports on CRAB; 4) detection of class A, B and D carbapenemases by molecular methods such as reverse-transcriptase polymerase chain reaction testing (RT-PCR) or MLST; 5) carbapenemase genotype analysis in LAC or China published in 2015-2020 in English, Spanish or Chinese.

Exclusion criteria Studies with one or more of the following characteristics were excluded: 1) contained no information on CRAB; 2) studied isolation in pediatric populations; 3) did not report on class A, B and D carbapenemase classes; 4) duplicated other research; and 5) studies that reported experiments in nonhuman subjects or were review articles, conference abstracts, meta-analyses or systemic reviews.

Review articles and meta-analyses were only considered in this review's discussion section. Screening for inclusion was carried out individually by two team members. When there were differences of opinion, these were discussed with the principal investigator. Endnote X9 and Excel were used to manage references.

Study quality evaluation Study quality was evaluated by two researchers using the JBI Critical Appraisal Tools for Prevalence Studies.[11] This tool includes nine items, each of which was scored as either 'Yes' (when the requirement was met), as 'No' (when the requirement was not met) or as 'Not Clear' (if it was unknown whether the requirement was met) or as 'Not Applicable'.[11] Studies were considered high quality when their score was $\geq 80 \%$ of the maximum possible score ( 8 or more items scored "Yes"), average quality when their score was $70 \%-79 \%$ (6-7 items scored 'Yes'), and low quality when their score was $<70 \%$ (6 or fewer items scored 'Yes').

Data extraction Two team members carried out data selection and extraction individually, as well as bias risk analysis. We organized data on carbapenemase genotypes in China, Latin America and the Caribbean into a matrix (Table 1).

\section{Table 1: Data extraction characteristics}

\begin{tabular}{l|l} 
Term & Definition \\
\hline Registration & Title, author, publication year \\
Study & Study type and investigation period \\
Region & Latin American and Caribbean countries and \\
Chinese provinces
\end{tabular}

CRAB: Carbapenem-resistant $A$. baumannii; MLST: Multilocus sequence typing; RT-PCR: Reverse-transcriptase polymerase chain reaction

Data analysis and statistics We carried out a quantitative study (meta-analysis) on A. baumannii carbapenemase genotypes and a qualitative study (qualitative descriptive synthesis) for sequence types, due to the great diversity of sequence types and differences between geographical areas. Two investigators undertook data analysis for the quantitative study. Statistical analysis was performed using the Metaprop module of Stata version 15 (StataCorp LLC U.S.A),[12] and obtained estimates of the combined prevalence of predominant $A$. baumannii carbapenemases in different regions, as well as their $95 \%$ confidence intervals $(95 \% \mathrm{Cl})$, which are represented in corresponding forest graphs (Figure 2).

We used either fixed-effect or random-effect models according to statistical heterogeneity between studies, which was assessed using the Cochran 12 statistic (a value of $0 \%$ indicates no heterogeneity; $25 \%, 50 \%$ and $75 \%$ are considered to have low, medium and high heterogeneity, respectively). Egger's weighted linear regression test, combined with a funnel plot, was used to assess publication bias. An assessment of 'no publication bias' was made when the regression line started from the origin of the ordinate axis $(Y)$ (publication bias increases as the line moves away from the $Y$ coordinate's origin). Statistical significance was assessed at 0.1 and not 0.05.[13]

\section{DEVELOPMENT}

Literature search, selection and validation We initially selected 334 articles, which were reduced to 318 after eliminating duplicates. Of these, 261 were excluded for failure to meet inclusion criteria or because they were outside the scope of this review. Finally, we fully reviewed a total of 57 articles, and 29 were selected that met all established criteria, which were then included in the meta-analysis (Figure 1).

Medium-high scores were obtained upon evaluation of the crosssectional observational studies (Table 2). In this study, $95 \%$ is 
used as expected prevalence in calculating sample size, as carbapenemase production is the CRAB's dominant cause. Considering three studies on molecular isolate typing in hospitals,[14-16] the confidence level equal to $95 \%$ and precision equal to $5 \%$, the estimated minimum CRAB sample size was 73 . Consequently, we excluded 14 articles due to small sample size. Another 14 studies on carbapenemase genoptyping were excluded for only reporting detection of Class $D$ carbapenemases.

Carbapenemase characteristics of the 29 studies included in this systematic review, 12 were from LAC, involving 11 countries and 17 were from 11 Chinese provinces. OXA-type carbapenemases were detected in all studies. In LAC, OXA-23, OXA-24, OXA-58 and OXA-72 genotypes were predominant, with respective prevalences of $0.73(0.54-0.89)$, 0.06 (0.00-0.17), $0.03(0.01-0.06)$ and 0.02 (0.00-0.06). In China, OXA-23, OXA-24 and OXA-72 were the most common, with respective prevalences of $0.91(0.84-0.96), 0.03$ (0.01-0.08), 0.02 (0.00-0.05).

Metallobetalactamases were less frequent than OXAs and were detected in only two countries in the Latin American and Caribbean region, with NDM $0.01(0.00-0.01)$ as the predominant genotype, and in six Chinese provinces, with four predominant genotypes: NDM $0.02(0.00-0.04)$, VIM $0.07(0.00-0.21)$, IPM $0.02(0.00-0.06)$ and SIM $0.01(0.00-0.03)$ (Table 3). Only one clinical isolate Class A carbapenemase producer (KPC) was found, and it was isolated in Colombia.

\section{Figure 1: Literature selection results (PRISMA)}

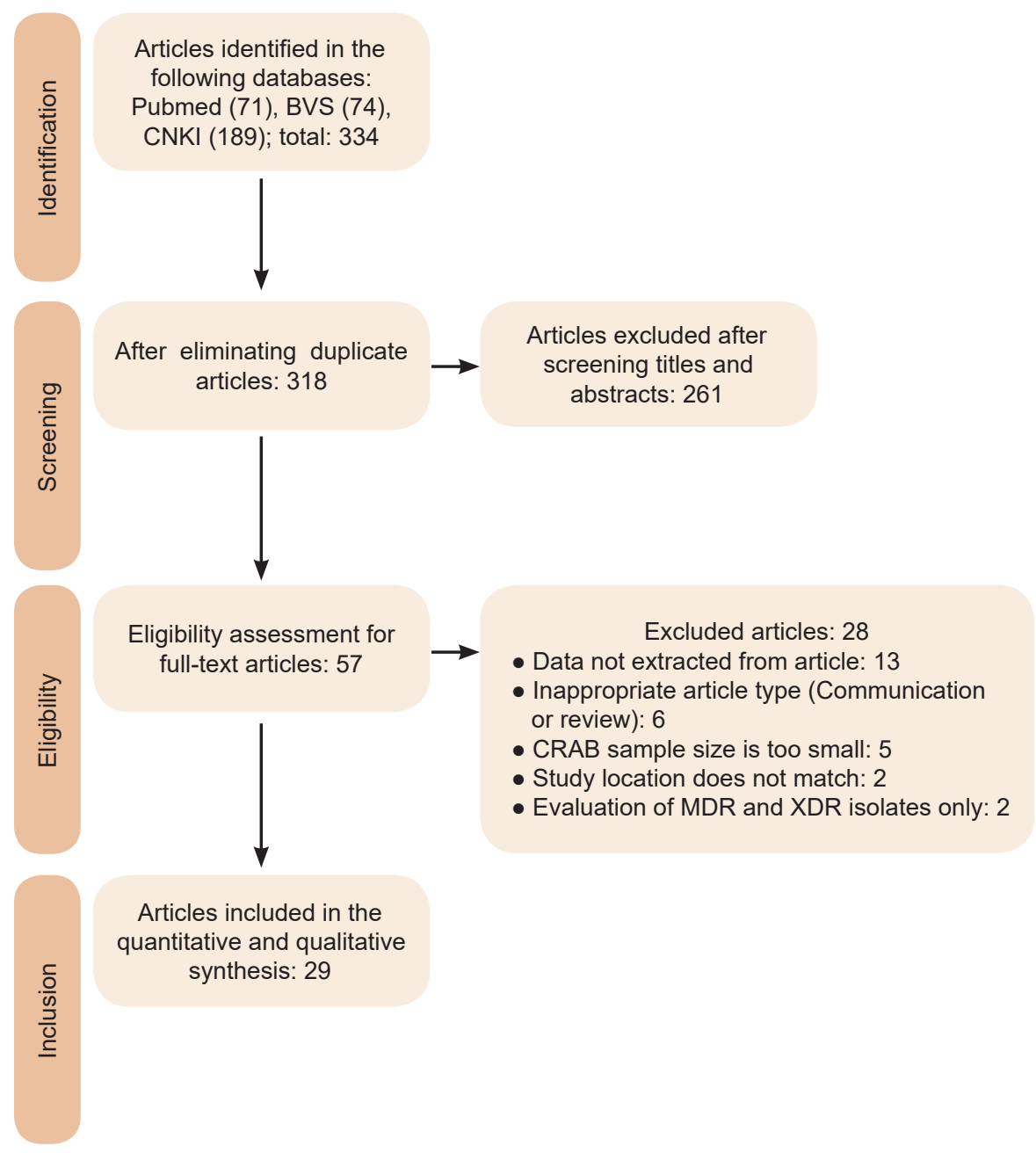

CRAB: Carbapenemase resistant Acinetobacter baumannii; MDR: Multi-drug resistant; PRISMA: Preferred Reporting Items for Systematic Reviews and Meta-Analyses; XDR: Extensively drug-resistant
According to the 12 values, high heterogeneity was observed among studies and we consequently used a random-effects model for the meta-analysis. Egger tests $(p>0.1)$ and funnel plots show the characteristic shape of the asymmetric dispersion (Table 3 and Figure 2).

Molecular typing characteristics In 17 of the 29 studies, MLST was performed on CRAB isolates. In total, 41 sequence types (STs) were identified: 16 in LAC and 26 in China. Clear geographical differences were observed in predominant ST frequencies: ST79, ST25, ST1 and ST15 were more common in LAC; while ST195, ST208, ST191, ST368 and ST369 were found more frequently in China. ST2 was found in both (Table 2 and Figure 3).

\section{DISCUSSION}

Carbapenemase types Antibiotic overuse has led to an increase in multi-drug-resistant Acinetobacter. More than $50 \%$ of Acinetobacter spp. isolates in the United States, South America, India and China are resistant to carbapenem antiobiotics.[46] This study verifies the high prevalence of OXAs in CRAB isolates in China, Latin America and the Caribbean. OXA-51-like carbapenemases (including OXA-51, 64, 65, 66, 68, 69, 70, 71, 78, 79,
80 and 82) occur naturally in A. baumannii.[47] OXA-24-like carbapenemases (including OXA-24, 25, 26, 40 and 72) have been found in both plasmid and chromosomal structures; OXA-58-like and OXA-23-like carbapenemases are encoded by plasmids,[48] which increases the probability of horizontal transmission. The plasmid-encoded carbapenemases OXA-23, OXA-24 and OXA58 were the most frequently isolated carbapenemases in the two regions analyzed in this study. These results justify the noninclusion of OXA-51 type carbapenemases, as their resistance to $C R A B$ is intrinsic, and thus has little impact on amplifying carbapenem resistance in this species.

Carbapenemase OXA-72 was first identified in 2004 in an A. baumannii isolate from Thailand,[49] and subsequently detected in Brazil, Mexico, Ecuador, Peru, China and Europe. $[27,43,45,50,51]$ PXA-231 and OXA-253 were identified in Brazil and Peru, respectively. Both belong to the OXA-143-like group. OXA-231 and OXA-253 were reported the first time in A. baumannii isolates from Brazil (in 2007 and 2014, respectively) and still appear mainly in that country.[52,53] The dissemination of this subgroup requires monitoring, as it has been described more recently in Iran (2017), Colombia (2017) and Peru (2018). $[45,54,55]$ 
Table 2: Studies included in the systematic review

\begin{tabular}{|c|c|c|c|c|c|c|c|c|c|c|c|c|}
\hline \multirow[b]{2}{*}{$\begin{array}{l}\text { Author, year, } \\
\text { reference }\end{array}$} & \multirow[b]{2}{*}{ Year isolated } & \multirow[b]{2}{*}{$\begin{array}{l}\text { Detection } \\
\text { method }\end{array}$} & \multirow[b]{2}{*}{ Place } & \multirow[b]{2}{*}{$\begin{array}{l}\text { Number } \\
\text { of CRAB } \\
\text { isolates }\end{array}$} & \multicolumn{3}{|c|}{ Carbapenem type (number detected) } & \multirow[b]{2}{*}{$\begin{array}{l}\text { Sequence type } \\
(\mathrm{n} / \mathrm{N})\end{array}$} & \multirow[b]{2}{*}{$\begin{array}{l}\text { The study } \\
\text { met all } \\
\text { selection } \\
\text { and quality } \\
\text { criteria }^{\&}\end{array}$} & \multicolumn{2}{|c|}{$\begin{array}{l}\text { The study did not meet } \\
\text { these quality criteria: }\end{array}$} & \multirow[b]{2}{*}{$\begin{array}{l}\text { Study } \\
\text { quality }\end{array}$} \\
\hline & & & & & Class A & Class B & Class D & & & $\begin{array}{c}\text { Adequate } \\
\text { sample } \\
\text { size }\end{array}$ & \begin{tabular}{|c|} 
Data analysis \\
with sufficient \\
coverage of \\
identified \\
sample
\end{tabular} & \\
\hline Chen F. (2018)[17] & 2011 & PCR & Hu Nan & 34 & NA & IMP-5(22) & $\begin{array}{l}\text { OXA-23(33) } \\
\text { OXA-24(29) }\end{array}$ & NA & No & $\mathrm{x}$ & $\mathrm{x}$ & Medium \\
\hline Chen Y. (2018)[18] & 2013-2017 & PCR & Guang Dong & 66 & ND & NDM-1(3) & $\begin{array}{l}\text { OXA-23(60) } \\
\text { OXA-24(19) } \\
\text { OXA-58(3) }\end{array}$ & NA & No & $x$ & - & High \\
\hline Chen Y. (2017)[19] & $2011-2013$ & PCR/MLST & Shang Hai & 56 & NA & ND & OXA-23(56) & $\begin{array}{l}\text { ST208(28/56) } \\
\text { ST191(12/56) } \\
\text { ST540(7/56) }\end{array}$ & No & $\mathrm{x}$ & $x$ & Media \\
\hline Han L. (2017)[20] & 2013 & PCR & Shan Xi & 45 & ND & ND & OXA-23(44) & NA & No & $x$ & - & High \\
\hline $\begin{array}{l}\text { Huang ZY. (2019) } \\
\text { [21] }\end{array}$ & 2016 & PCR/MLST & Hu Nan & 67 & NA & VIM(54) & $\begin{array}{l}\text { OXA-23(63) } \\
\text { OXA-58(1) }\end{array}$ & $\begin{array}{l}\text { ST195(28/67) } \\
\text { ST368(9/67) } \\
\text { ST829(8/67) } \\
\text { ST210(2/67) } \\
\text { ST90(2/67) } \\
\text { ST136(2/67) }\end{array}$ & No & $x$ & $\mathrm{x}$ & Medium \\
\hline Jiang L. (2018)[22] & 2017 & $\mathrm{PCR} / \mathrm{MLST}$ & Guang Dong & 122 & NA & $\begin{array}{l}\operatorname{VIM}(7) \\
\operatorname{SIM}(2)\end{array}$ & OXA-23(115) & $\begin{array}{l}\text { ST195(10/28) } \\
\text { ST208(9/28) } \\
\text { ST1633(3/28) } \\
\text { ST345(1/28) } \\
\text { ST381(1/28) } \\
\text { ST457(1/28) }\end{array}$ & No & - & $x$ & High \\
\hline Zhao L. (2018)[23] & 2015-2016 & PCR & An Hui & 145 & ND & IMP-4(4) & $\begin{array}{l}\text { OXA-23(134) } \\
\text { OXA-24(1) }\end{array}$ & NA & Yes & - & - & High \\
\hline Song X. (2017)[24] & 2013-2014 & PCR & Shan Dong & 32 & ND & $\operatorname{VIM}(3)$ & OXA-23(28) & NA & No & $\mathrm{x}$ & - & High \\
\hline Chen J. (2017)[25] & 2015-2016 & PCR & Jiang $\mathrm{Xi}$ & 64 & ND & $\begin{array}{l}\operatorname{VIM}(56) \\
\text { NDM-1(17) } \\
\text { SIM(12) }\end{array}$ & $\begin{array}{l}\text { OXA-23(56) } \\
\text { OXA-24(2) }\end{array}$ & NA & No & $\mathrm{x}$ & - & \\
\hline $\begin{array}{l}\text { Huang G. (2016) } \\
\text { [26] }\end{array}$ & 2012-2014 & PCR/MLST & Chong Qing & 248 & NA & NA & OXA-23(163) & $\begin{array}{l}\text { ST368 }(102 / 248) \\
\text { ST195 }(31 / 248) \\
\text { ST191 }(29 / 248) \\
\text { ST369 }(29 / 248) \\
\text { ST208 }(21 / 248) \\
\text { ST381 }(7 / 248) \\
\text { ST136 }(2 / 248) \\
\text { ST229 }(1 / 248) \\
\text { ST457 }(1 / 248)\end{array}$ & Yes & - & - & High \\
\hline Chen Y. (2018)[27] & 2014-2016 & PCR/MLST & Liao Ning & 78 & NA & ND & $\begin{array}{l}\text { OXA-23(33) } \\
\text { OXA-72(45) }\end{array}$ & ST2(9/78) & No & - & $\mathrm{x}$ & High \\
\hline
\end{tabular}




\begin{tabular}{|c|c|c|c|c|c|c|c|c|c|c|c|c|}
\hline \multirow[b]{2}{*}{$\begin{array}{l}\text { Author, year, } \\
\text { reference }\end{array}$} & \multirow[b]{2}{*}{ Year isolated } & \multirow[b]{2}{*}{$\begin{array}{l}\text { Detection } \\
\text { method }\end{array}$} & \multirow[b]{2}{*}{ Place } & \multirow[b]{2}{*}{$\begin{array}{l}\text { Number } \\
\text { of CRAB } \\
\text { isolates }\end{array}$} & \multicolumn{3}{|c|}{ Carbapenem type (number detected) } & \multirow[b]{2}{*}{$\begin{array}{l}\text { Sequence type } \\
\text { (n/N) }\end{array}$} & \multirow[b]{2}{*}{$\begin{array}{l}\text { The study } \\
\text { met all } \\
\text { selection } \\
\text { and quality } \\
\text { criteria }^{\&}\end{array}$} & \multicolumn{2}{|c|}{$\begin{array}{l}\text { The study did not meet } \\
\text { these quality criteria: }\end{array}$} & \multirow[b]{2}{*}{$\begin{array}{l}\text { Study } \\
\text { quality }\end{array}$} \\
\hline & & & & & Class A & Class B & Class D & & & $\begin{array}{l}\text { Adequate } \\
\text { sample } \\
\text { size }\end{array}$ & $\begin{array}{c}\text { Data analysis } \\
\text { with sufficient } \\
\text { coverage of } \\
\text { identified } \\
\text { sample }\end{array}$ & \\
\hline Ning N. (2017)[29] & 2009-2014 & PCR/MLST & Bei Jing & 101 & NA & NA & $\begin{array}{l}\text { OXA-23(95) } \\
\text { OXA-40(1) }\end{array}$ & $\begin{array}{l}\text { ST191(32/101) } \\
\text { ST195(31/101) } \\
\text { ST208(15/101) } \\
\text { ST368(6/101) } \\
\text { ST469(6/101) } \\
\text { ST218(2/101) } \\
\text { ST373(2/101) } \\
\text { ST383(2/101) } \\
\text { ST429(2/101) } \\
\text { ST369(1/101) }\end{array}$ & No & - & 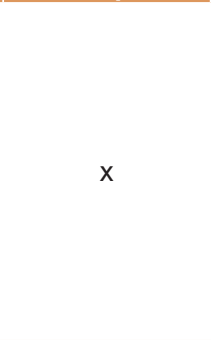 & High \\
\hline Lu Q. (2019)[30] & 2013-2015 & PCR & Guang Xi & 61 & NA & NDM-1(1) & OXA-23(44) & NA & No & $x$ & - & High \\
\hline Zhang Y. (2019)[31] & 2017 & PCR/MLST & An Hui & 28 & ND & ND & OXA-23(25) & $\begin{array}{l}\text { ST1779 }(8 / 28) \\
\text { ST1789(6/28) } \\
\text { ST195(5/28) } \\
\text { ST191(2/28) } \\
\text { ST368(2/28) } \\
\text { ST369(2/28) }\end{array}$ & No & $x$ & - & High \\
\hline Wu H. (2017)[32] & 2015-2016 & PCR/MLST & Shan Dong & 55 & NA & ND & OXA-23(55) & $\begin{array}{l}\text { ST208(21/55) } \\
\text { ST369(14/55) } \\
\text { ST195(11/55) } \\
\text { ST451(6/55) } \\
\text { ST381(1/55) }\end{array}$ & No & $\mathrm{x}$ & $x$ & Medium \\
\hline Li P. (2015)[33] & Not mentioned & PCR & Beijing & 145 & NA & NA & $\begin{array}{l}\text { OXA-23(134) } \\
\text { OXA-58(1) }\end{array}$ & NA & No & - & $x$ & High \\
\hline Bado I. (2018)[34] & 2010-2011 & PCR/MLST & Uruguay & 73 & ND & ND & $\begin{array}{l}\text { OXA-23(58) } \\
\text { OXA-58(2) }\end{array}$ & $\begin{array}{l}\text { ST79(20/73) } \\
\text { ST958(1/73) }\end{array}$ & Yes & - & - & High \\
\hline $\begin{array}{l}\text { Camargo } \mathrm{CH} \text {. } \\
(2016)[35]\end{array}$ & 2009-2013 & PCR/MLST & Brazil & 71 & ND & ND & $\begin{array}{l}\text { OXA-23(68) } \\
\text { OXA-72(2) }\end{array}$ & $\begin{array}{l}\text { ST79(16/71) } \\
\text { ST1(16/71) } \\
\text { ST15(20/71) }\end{array}$ & No & $x$ & - & High \\
\hline $\begin{array}{l}\text { Castilho SRA. } \\
(2017)[36]\end{array}$ & 2010 & PCR & Brazil & 51 & NA & NA & $\begin{array}{l}\text { OXA-23(31) } \\
\text { OXA-58(2) }\end{array}$ & NA & No & $x$ & $\mathrm{x}$ & Medium \\
\hline $\begin{array}{l}\text { Castillo Y. (2019) } \\
\text { [37] }\end{array}$ & 2008-2013 & PCR & Perú & 46 & ND & ND & $\begin{array}{l}\text { OXA-23(44) } \\
\text { OXA-24(1) }\end{array}$ & NA & No & $x$ & - & High \\
\hline $\begin{array}{l}\text { Gonzalez-Villoria } \\
\text { AM. (2016)[38] }\end{array}$ & 2006-2013 & PCR/MLST & México & 192 & NA & ND & $\begin{array}{l}\text { OXA-24(70) } \\
\text { OXA-23(57) } \\
\text { OXA-58(23) }\end{array}$ & $\begin{array}{l}\text { ST758(9/22) } \\
\text { ST417(2/22) }\end{array}$ & No & - & $x$ & High \\
\hline $\begin{array}{l}\text { Opazo-Capurro A. } \\
(2019)[40]\end{array}$ & 1990-2015 & PCR/MLST & Chile & 56 & NA & ND & $\begin{array}{l}\text { OXA-23(17) } \\
\text { OXA-58(17) }\end{array}$ & $\begin{array}{l}\text { ST162(4/56) } \\
\text { ST15(3/56) } \\
\text { ST109(2/56) } \\
\text { ST318(1/56) }\end{array}$ & No & $x$ & $\mathrm{x}$ & Medium \\
\hline $\begin{array}{l}\text { Ovalle MV. (2017) } \\
\text { [41] }\end{array}$ & 2012-2014 & PCR & Colombia & 97 & $\mathrm{KPC}(1)$ & $\begin{array}{l}\operatorname{NDM}(3) \\
\operatorname{VIM}(1)\end{array}$ & $\begin{array}{l}\text { OXA-23(87) } \\
\text { OXA-24(1) }\end{array}$ & NA & Yes & - & - & High \\
\hline $\begin{array}{l}\text { Quiñones D. (2015) } \\
\text { [42] }\end{array}$ & 2010-2012 & PCR & Cuba & 220 & NA & NDM (1) & $\begin{array}{l}\text { OXA-23(130) } \\
\text { OXA-24(35) } \\
\text { OXA-58(5) }\end{array}$ & NA & Yes & - & - & High \\
\hline
\end{tabular}




\begin{tabular}{|c|c|c|c|c|c|c|c|c|c|c|c|c|}
\hline \multirow[b]{2}{*}{$\begin{array}{l}\text { Author, year, } \\
\text { reference }\end{array}$} & \multirow[b]{2}{*}{ Year isolated } & \multirow[b]{2}{*}{$\begin{array}{l}\text { Detection } \\
\text { method }\end{array}$} & \multirow[b]{2}{*}{ Place } & \multirow[b]{2}{*}{$\begin{array}{l}\text { Number } \\
\text { of CRAB } \\
\text { isolates }\end{array}$} & \multicolumn{3}{|c|}{ Carbapenem type (number detected) } & \multirow[b]{2}{*}{$\begin{array}{l}\text { Sequence type } \\
(n / N)\end{array}$} & \multirow[b]{2}{*}{$\begin{array}{l}\text { The study } \\
\text { met all } \\
\text { selection } \\
\text { and quality } \\
\text { criteria }^{\&}\end{array}$} & \multicolumn{2}{|c|}{$\begin{array}{l}\text { The study did not meet } \\
\text { these quality criteria: }\end{array}$} & \multirow[b]{2}{*}{$\begin{array}{l}\text { Study } \\
\text { quality }\end{array}$} \\
\hline & & & & & Class A & Class B & Class D & & & $\begin{array}{l}\text { Adequate } \\
\text { sample } \\
\text { size }\end{array}$ & $\begin{array}{c}\text { Data analysis } \\
\text { with sufficient } \\
\text { coverage of } \\
\text { identified } \\
\text { sample }\end{array}$ & \\
\hline $\begin{array}{l}\text { Brisolla LC (2019) } \\
\text { [44] }\end{array}$ & 2008-2014 & PCR/MLST & Brazil & 107 & NA & NA & $\begin{array}{l}\text { OXA-23(104) } \\
\text { OXA-231(2) } \\
\text { OXA-72(1) }\end{array}$ & $\begin{array}{l}\text { ST730 }(43 / 107) \\
\text { ST317(28/107) } \\
\text { ST1 }(10 / 107) \\
\text { ST79 }(8 / 107) \\
\text { ST107(2/107) } \\
\text { ST986(1/107) } \\
\text { ST175(1/107) } \\
\text { ST22(1/107) }\end{array}$ & No & - & $x$ & High \\
\hline $\begin{array}{l}\text { Levy-Blitchtein S. } \\
\text { (2018)[45] }\end{array}$ & 2014-2016 & PCR/MLST & Perú & 78 & ND & ND & $\begin{array}{l}\text { OXA-23(11) } \\
\text { OXA-24(55) } \\
\text { OXA-72(10) } \\
\text { OXA-253(2) }\end{array}$ & $\begin{array}{l}\text { ST2 }(7 / 16) \\
\text { ST79 }(6 / 16) \\
\text { ST1 }(2 / 16) \\
\text { ST3(2/16) } \\
\text { ST108(1/16) }\end{array}$ & Yes & - & - & High \\
\hline
\end{tabular}

\section{All were cross-sectional studies.}

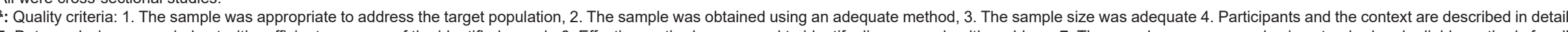

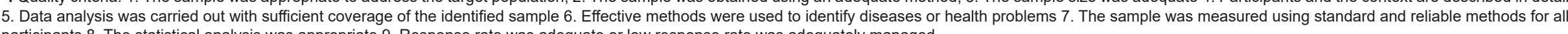
participants 8 . The statistical analysis was appropriate 9. Response rate was adequate or low response rate was adequately managed.

n: number of times the sequence was found; N: total isolates studied; NA: Not applicable (detection not performed); ND: Not detected;

$\mathrm{X}$ : did not meet the requirement; -: met the requirement. 
Table 3: Meta-analysis of carbapenemase genotypes in China, Latin America and the Caribbean

\begin{tabular}{|c|c|c|c|c|c|c|c|c|}
\hline Place & Subs & oups & $\begin{array}{l}\text { Number of } \\
\text { studies }\end{array}$ & $n / N$ & $\begin{array}{l}\text { Prevalence } \\
(95 \% \mathrm{CI})\end{array}$ & $\begin{array}{l}\text { Heterogeneity, } \\
\text { I2 (\%) }\end{array}$ & $\begin{array}{c}\text { Heterogeneity } \mathbf{p} \\
\text { value }\end{array}$ & Egger's test \\
\hline \multirow{8}{*}{$\begin{array}{l}\text { Latin America and } \\
\text { the Caribbean }\end{array}$} & \multirow{4}{*}{ Class D } & OXA-23 & 11 & $804 / 1217$ & $0.73(0.54-0.89)$ & 98.06 & $>0.001$ & 0.42 \\
\hline & & OXA-24 & 11 & $162 / 1217$ & $0.06(0.00-0.17)$ & 96.96 & $>0.001$ & 0.36 \\
\hline & & OXA-58 & 11 & $49 / 1217$ & $0.03(0.01-0.06)$ & 85.97 & $>0.001$ & 0.87 \\
\hline & & OXA-72 & 11 & $42 / 1217$ & $0.02(0.00-0.06)$ & 88.20 & $>0.001$ & 0.94 \\
\hline & \multirow{4}{*}{ MBLs } & NDM & 9 & $4 / 933$ & $0.01(0.00-0.01)$ & 0.00 & $>0.05$ & 0.40 \\
\hline & & VIM & 9 & $1 / 933$ & - & - & - & - \\
\hline & & IMP & 9 & 0/933 & - & - & - & - \\
\hline & & SIM & 9 & 0/933 & - & - & - & - \\
\hline \multirow{8}{*}{ China } & \multirow{4}{*}{ Class D } & OXA-23 & 17 & $1290 / 1499$ & $0.91(0.84-0.96)$ & 94.42 & $>0.001$ & 0.36 \\
\hline & & OXA-24 & 17 & $51 / 1499$ & $0.03(0.01-0.08)$ & 92.34 & $>0.001$ & 0.11 \\
\hline & & OXA-58 & 17 & $5 / 1499$ & - & - & - & - \\
\hline & & OXA-72 & 17 & $45 / 1499$ & $0.02(0.00-0.05)$ & 91.07 & $>0.001$ & 0.66 \\
\hline & \multirow{4}{*}{ MBLs } & NDM & 14 & $21 / 1005$ & $0.02(0.00-0.04)$ & 74.58 & $>0.001$ & 0.57 \\
\hline & & VIM & 14 & $120 / 1005$ & $0.07(0.00-0.21)$ & 97.36 & $>0.001$ & 0.60 \\
\hline & & IMP & 14 & $26 / 1005$ & $0.02(0.00-0.06)$ & 85.77 & $>0.001$ & 0.21 \\
\hline & & SIM & 14 & $14 / 1005$ & $0.01(0.00-0.03)$ & 57.92 & $>0.001$ & 0.54 \\
\hline
\end{tabular}

MBLs: Metallobetalactamases; $\mathrm{n}$ : Number of isolates with the genotype; $\mathrm{N}$ : Total number of carbapenem-resistant $A$. baumannii isolates

Number of studies: number of studies in which carbapenemases were identified

Figure 2: Forest plot and funnel plot for OXA-23 carbapenemase prevalence in China, Latin America and the Caribbean
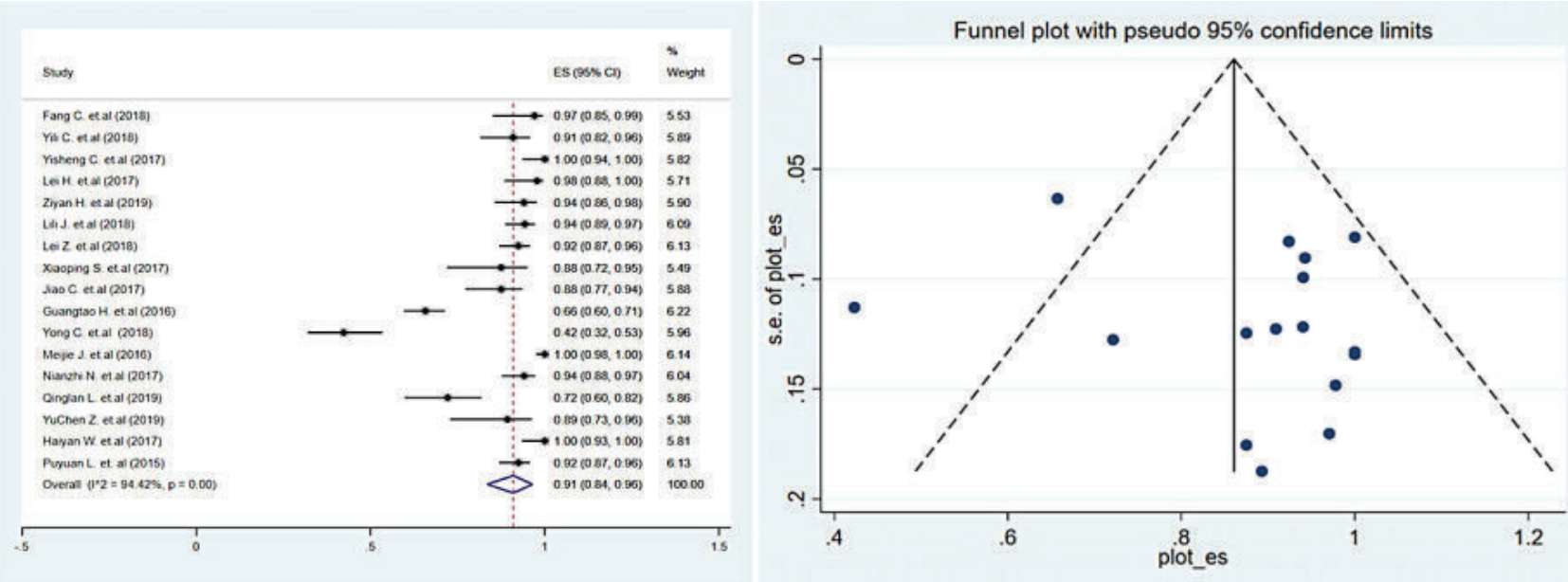

(A)
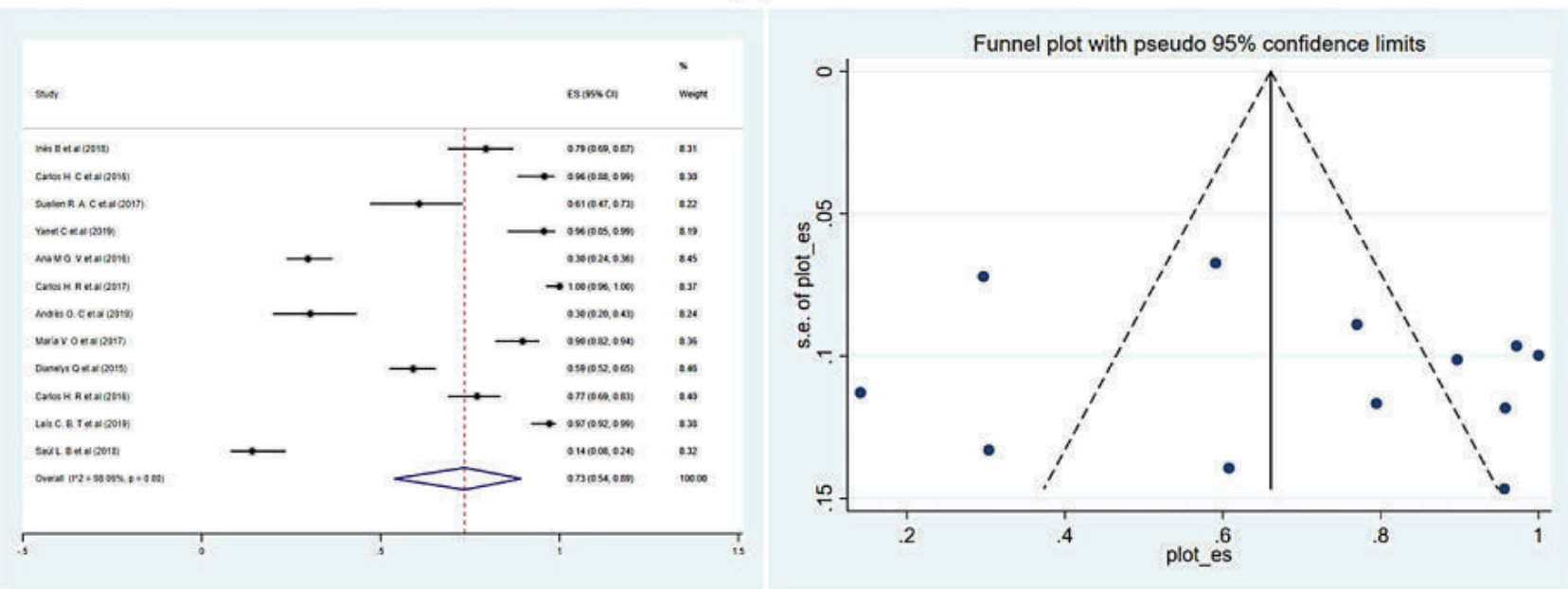

(B)

A: OXA-23 carbapenemase prevalence in China

B: OXA-23 carbapenemase prevalence in Latin America and the Caribbean 
Figure 3: Acinetobacter baumannii sequence type (ST) geographic distribution in China, Latin America and the Caribbean

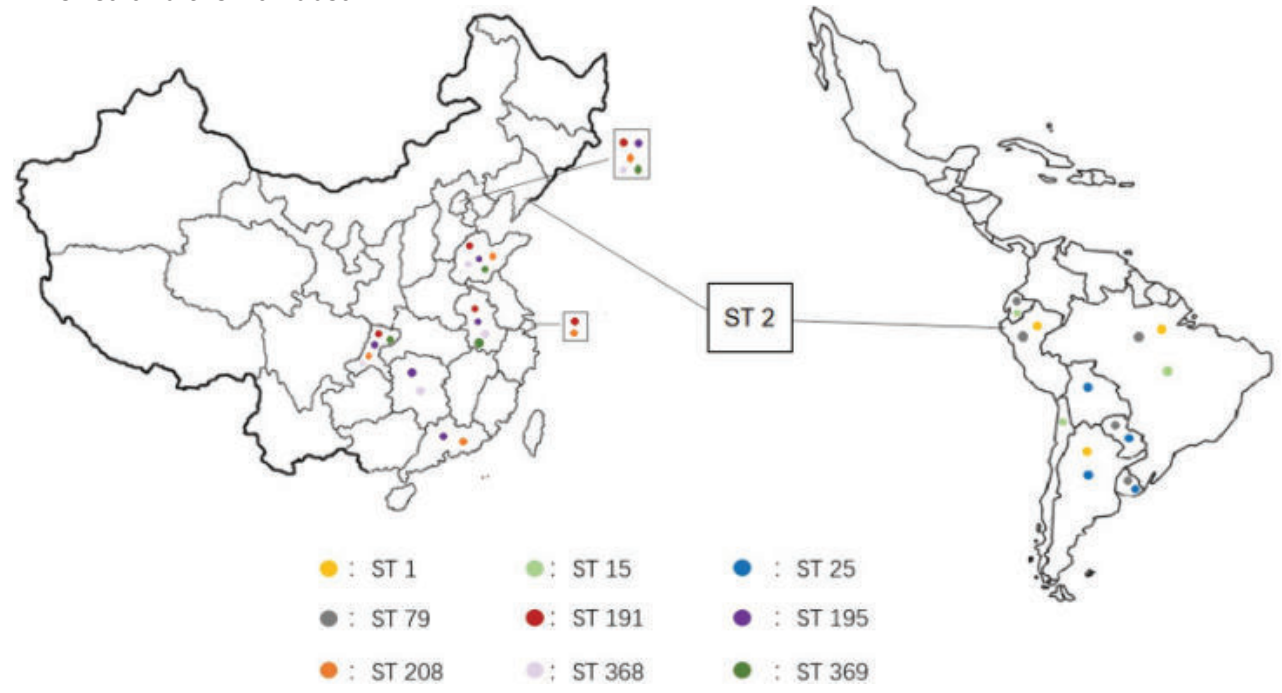

Eight provinces in China conducted multilocus sequence studies using MLST; ST195 and ST208 were the most common. These two sequence types have been found in other regions of the world and tend to become the dominant STs once introduced.[6365] A study of the clinical and molecular characteristics of CRAB-produced bacteremia in China showed clones ST195 and ST208 to be predominant, and bacteremia resulting from $A$. baumannii clone ST195 was associated with higher lethality.[66] Clones ST191, ST368 and ST369 are moderately prevalent in China and are more commonly found in Asia than the rest of the world. Hospital infection by $A$. baumannii clones ST191 and ST369 has also been reported in China and South Korea.[67,68] The STs that are the most common in China are rarely reported in LAC; only ST369 has been reported in Mexico in 2020.[69] This may be the result of differing clonal ancestries in both regions and selection pressure from different antimicrobial use habits.

ST2 was found in both regions (Peru in LAC and Liao Ning in China). ST2 is prevalent in some countries in Pacific Asia and Europe,[70-74] but has not been reported with any frequency in LAC in the last five years. Although this study found ST2 to be associated with OXA-72, other studies have described ST2 A. baumannii clones as mainly being producers of OXA-23.[74-76] ST2's dissemination in LAC merits consideration.

This study has provided estimates of the prevalence of different types of carbapenemases in A. baumannii in LAC and China, and the geographical distribution of different circulating CRAB STs and supports adjustments to resistance surveillance programming and antimicrobial management.

Study limitations There were some Latin American and Caribbean countries and Chinese provinces that produced no studies that met our selection criteria. Consequently, there is no information on carbapenemase-producing CRAB strain genotypes in these regions. Additionally, most studies do not detect Class $A$ carbapenemases. This exclusion may have led to an overrepresentation of other carbapenemase classes and this preferential study of certain classes may have introduced bias. Finally, while the Egger test in not statistically significant and publication bias is unlikely, there is considerable heterogeneity between studies, as suggested by the asymmetric and sparse shape of the funnel plots. This could be due to insufficient sample size in the included studies, or to some variation (either geographical or temporal) in the strains or other methodological aspects such as differences in sample inclusion and exclusion criteria, among other factors.

\section{CONCLUSION}

A. baumannii resistance to carbapenem antibiotics is a global threat, and there is increasing diffusion of carbapenem-producing A. baumannii isolates and increasing geographic ST variation. Enzymes produced by regional isolates are generally very simi- 
lar, while differences in STs are observed between China, Latin America and the Caribbean. Different regions have different epidemic CRAB strains, and it is important to consider local epidemiology in order to best tailor patient treatment. Studying circulating enzymes, clones and genetic lines facilitates understanding of region-specific resistance mechanisms.

Multidisciplinary collaboration is necessary (microbiologists, clinicians, epidemiologists and specialists in preventive medicine with experience in infection control), and will allow for early detection and study of resistance using molecular methods; adequate treatment, taking into consideration the patient's clinical status, common circulating strains, and infection characteristics; and adoption of epidemiological measures aimed at multi-drug-resistant infection prevention and control, reducing transmission at community- and hospital levels. A multidisciplinary approach can provide better results in managing a complex, multifactorial problem with major implications for public health. $-1 /$ -

\section{REFERENCES}

1. Wareth G, Brandt C, Sprague LD, Neubauer $\mathrm{H}$, Pletz MW. Spatio-temporal distribution of Acinetobacter baumannii in Germany-a comprehensive systematic review of studies on resistance development in humans (2000-2018). Microorganisms [Internet]. 2020 Mar 6 [cited 2021 Jun 25]8(3):375. Available at: https://www .mdpi.com/2076-2607/8/3/375

2. Viehman JA, Nguyen MH, Doi Y. Treatment options for carbapenem-resistant and extensively drug-resistant Acinetobacter baumannii infections. Drugs [Internet]. 2014 Aug 5 [cited 2021 Jun 25];74(12):1315-33. Available at: https://doi .org/10.1007/s40265-014-0267-8

3. Pan American Health Organization [Internet]. Washington, D.C.: Pan American Health Organization; c2021. Documents. Magnitud y tendencias de la resistencia a los antimicrobianos en Latinoamérica. RELAVRA 2014, 2015, 2016. Informe resumido Organización Panamericana de Salud; 2020 Oct 16 [cited 2021 Jun 25]. Available at: https://www.paho.org/es/documentos/magnitud -tendencias-resistencia-antimicrobianos-latino america-relavra-2014-2015-2016. Spanish.

4. Hu F, Guo Y, Zhu DM, Wang F, Jiang XF, Xu YC, et al. [CHINET surveillance of bacterial resistance across China: report of the results in 2016]. Chin J Infect Chemother [Internet]. 2017 [cited 2021Apr 13];17(5):481-91. Available at: http:// wprim.whocc.org.cn/admin/article/articleDetail? WPRIMID $=668380 \&$ articleld $=668380$. Chinese.

5. World Health Organization [Internet]. Geneva: World Health Organization; c2021. Press release. WHO publishes list of bacteria for which new antibiotics are urgently needed; 2017 Feb 27 [cited 2021 Jun 3]; [about 3 p.]. Available at: https://www.who.int/es/news/ item/27-02-2017-who-publishes-list-of-bacteria -for-which-new-antibiotics-are-urgently-needed

6. Jeannot K, Diancourt L, Vaux S, Thouverez M, Ribeiro A, Coignard B, et al. Molecular epidemiology of carbapenem non-susceptible Acinetobacter baumannii in France. PLoS One [Internet]. 2014 Dec 17 [cited 2021 Jun 25];9(12):e115452. Available at: https://journals.plos.org/plosone/ article?id=10.1371/journal. pone.0115452

7. Ranjbar R, Zayeri S, Mirzaie A. Development of multiplex PCR for rapid detection of metallo- $\beta$ lactamase genes in clinical isolates of Acinetobacter baumannii. Iranian J Microbiol [Internet]. 2020 Apr [cited 2021 Jun 25];12(2):107-12. Available at: https://www.ncbi.nlm.nih.gov/pmc/ articles/PMC7244819/

8. Bartual SG, Seifert H, Hippler C, Domínguez Luzon MA, Wisplinghoff $H$, Rodríguez-Valera F. Development of a multilocus sequence typing scheme for characterization of clinical isolates of Acinetobacter baumannii. J Clin Microbiol [Internet]. 2020 Dec 21 [cited 2021 Jun 30];43(9):4382-90. Available at: https://jour nals.asm.org/doi/abs/10.1128/JCM.43.9.4382 $-4390.2005$

9. Cooke A, Smith D, Booth A. Beyond PICO: The SPIDER tool for qualitative evidence synthesis.
Qual Health Res [Internet]. 2012 Oct [cited 2021 Apr 13];22(10):1435-43. Available at: https://doi .org/10.1177/1049732312452938

10. Moher D, Liberati A, Tetzlaff J, Altman DG. Ítems de referencia para publicar revisiones sistemáticas y metaanálisis: la Declaración PRISMA [Preferred reporting items for systematic reviews and meta-analyses: The PRISMA Statement]. Rev Esp Nutr Hum Diet [Internet]. 2014 Sep 16 [cited 2020 Jun 6];18(3):172-81. Available at: https://do .org/10.14306/renhyd.18.3.114. Spanish, English.

11. Munn Z, Moola S, Lisy K, Riitano D, Tufanaru C. Methodological guidance for systematic reviews of observational epidemiological studies reporting prevalence and cumulative incidence data. Int J Evid Based Healthc [Internet] 2015 Sep [cited 2020 Jul 25];13(3):147-53. Available at: https://journals.Iww.com/ijebh/Full text/2015/09000/Methodological_guidance_for systematic reviews of.6.aspx

12. Nyaga VN, Arbyn M, Aerts M. Metaprop: a Stata command to perform meta-analysis of binomial data. Arch Public Health [Internet]. 2014 Nov 10 [cited $2020 \mathrm{Jul}$ 7];72(39). Available at: https://doi .org/10.1186/2049-3258-72-39

13. Molina Arias M. Aspectos metodológicos del metaanálisis (1). Pediatr Atención Primaria [Internet]. 2018 Jul-Sep [cited 2020 Jul 7];20(79):297-302. Available at: http://sci elo.isciii.es/scielo.php?script=sci_arttext\&pid =S1139-76322018000300020. Spanish.

14. Hamidian M, Nigro SJ. Emergence, molecular mechanisms and global spread of carbapenem-resistant Acinetobacter baumannii. Microb Genom [Internet]. 2019 Oct [cited 2021 May 13];5(10):e000306. Available at: https://www .ncbi.nlm.nih.gov/pmc/articles/PMC6861865/

15. de Oliveira EA, de Paula GR, Mondino PJJ, Gomes Chagas TP, Bona de Mondino SS, Vieira de Mendonca-Souza CR. High rate of detection of OXA-23-producing Acinetobacter from two general hospitals in Brazil. Rev Soc Brasileira Med Trop [Internet]; 2019 Sep 5 [cited 2021 May 13];52:e20190243. Available at: https://doi .org/10.1590/0037-8682-0243-2019

16. Zhao L, Liu SY, Li JB, Ye Y. [A multicenter study of hospital infection with carbapenem-resistant Acinetobacter baumannii]. Chin J Infect Dis [Internet]. 2018 [cited 2021 May 13];36. Available at: https://doi.org/10.3760/cma.j.is sn.1000-6680.2018.04.005. Chinese.

17. Chen F, Wang L, Wang M, Xie Y, Xia X, Li X, et al. Genetic characterization and in vitro activity of antimicrobial combinations of multidrug-resistant Acinetobacter baumannii from a general hospital in China. Oncol Lett [Internet]. 2018 Feb [cited 2020 Aug 20];15(2):2305-15. Available at: https://www.ncbi.nlm.nih.gov/pmc/articles/ PMC5776888/

18. Chen $\mathrm{Y}, \mathrm{Ai} \mathrm{L}$, Guo $\mathrm{P}$, Huang $\mathrm{H}$, Wu Z, Liang $\mathrm{X}$, et al. Molecular characterization of multidrug resistant strains of Acinetobacter baumannii isolated from pediatric intensive care unit in a Chinese tertiary hospital. BMC Infect Dis [Internet].
2018 Dec 4 [cited 2020 Aug 15];15(2):2305-15. Available at: https://doi.org/10.1186/s12879-018 $-3511-0$

19. Chen $Y$, Gao J, Zhang H, Ying C. Spread of the blaOXA-23-containing Tn2008 in carbapenemresistant Acinetobacter baumannii isolates grouped in CC92 from China. Front Microbiol [Internet]. 2017 Feb [cited 2020 Aug 20];8:163. Available at: https://www.ncbi.nlm.nih.gov/pmc/ articles/PMC5292404/

20. Han L, Lei J, Xu J, Han S. blaOXA-23-like and blaTEM rather than blaOXA-51-like contributed to a high level of carbapenem resistance in Acinetobacter baumannii strains from a teaching hospital in Xi'an, China. Medicine (Baltimore) [Internet]. $2017 \mathrm{Dec}$ [cited 2020 Aug 15];96(48):e8965. Available at: https://www.ncbi .nlm.nih.gov/pmc/articles/PMC5728800/

21. Huang ZY, Li J, Shui J, Wang HC, Hu YM, Zou MX. Co-existence of blaOXA-23 and blaVIM in carbapenem-resistant Acinetobacter baumannii isolates belonging to global complex 2 in a Chinese teaching hospital. Chinese Med J (Engl) [Internet]. 2019 May 20 [cited 2020 Aug 15];132(10):1166-72. Available at: https://www .ncbi.nlm.nih.gov/pmc/articles/PMC6511418/

22. Jiang L, Liang $Y$, Yao W, Ai J, Wang $X$, Zhao $Z$. Molecular epidemiology and genetic characterisation of carbapenem-resistant Acinetobacter baumannii isolates from Guangdong Province, South China. J Glob Antimicrob Resist [Internet]. 2019 Jun [cited 2020 Sep 5];17:84-9. Available at: http://www.sciencedirect.com/science/article/ pii/S2213716518302182

23. Zhao L, Liu S, Li J, Ye Y. [A multicenter study of hospital infection with carbapenem-resistant Acinetobacter baumannii]. Chin J Infect Dis [Internet]. 2018 [cited 2020 Sep 20];36. Available at: http://rs.yiigle.com/CN311365201804/1050855 htm. Chinese.

24. Song X, Chen J, Zhai J, Zhu Y, Li C, Yang D. [A study on antibiotics resistance and carbapenemase genotype of Acinetobacter baumannii in intensive care unit of Qingdao]. Chin J Lab Med [Internet]. 2017 [cited 2020 Sep 9];40(3):21620. Chinese. Available at: http://rs.yiigle.com/ CN114452201703/978475.htm

25. Chen J, Xu X, Liu K, Hu X, Chen H, Chen K, et al. [NDM-1 gene and other carbapenemase genes in Acinetobacter baumannii in Jiangxi area]. Chin J Infect Control [Internet]. 2017 [cited 2020 Aug 25];2(16). Available at: https://kns.cnki.net/kcms/ detail/detail.aspx?dbcode=CJFD\&filename $=$ GRKZ 201702003\&dbname $=$ CJFDLAST2017. Chinese.

26. Huang G, Yin S, Gong Y, Zhao X, Zou L, Jiang $B$, et al. Multilocus sequence typing analysis of carbapenem-resistant Acinetobacter baumannii in a Chinese Burns Institute. Front Microbiol [Internet]. 2016 Nov 9 [cited 2020 Aug 25];7:1717. Available at: https://www.frontiersin .org/article/10.3389/fmicb.2016.01717

27. Chen Y, Yang Y, Liu L, Qiu G, Han X, Tian S, et al. High prevalence and clonal dissemination of OXA-72-producing Acinetobacter baumannii in a 
Chinese hospital: a cross sectional study. BMC Infect Dis [Internet]. 2018 Sep 29 [cited 2020 Aug 20];18:491. Available at: https://doi.org/10.1186/ s12879-018-3359-3

28. Jiang M, Liu L, Ma Y, Zhang Z, Li N, Zhang F, et al. Molecular epidemiology of multi-drug resistant Acinetobacter baumannii isolated in Shandong, China. Front Microbiol [Internet] 2016 Oct 21 [cited 2020 Sep 5];7:1687. Available at: https://www.frontiersin.org/articles/10.3389/ fmicb.2016.01687

29. Ning N, Liu X, Bao C, Chen S, Cui E, Zhang J, et al. Molecular epidemiology of blaOXA-23-producing carbapenem-resistant Acinetobacter baumannii in a single institution over a 65-month period in north China. BMC Infect Dis [Internet] 2017 Jan 5 [cited 2020 Sep 5];17:14. Available at: https://doi.org/10.1186/s12879-016-2110-1

30. Lu Q, Wei B, Li H, Zhang Y. [Drug resistance and genotyping of $\beta$-lactamase of Acinetobacter baumannii resistant to carbapenems in western Guangxi]. Lab Med Clin [Internet]. 2019 [cited 2020 Aug 20];16(12). Available at: https://kns.cnki .net $/ \mathrm{kcms} /$ detail/detail.aspx?dbcode $=$ CJFD\&dbn ame $=$ CJFDLAST2019\&filename $=J Y Y L 20191201$ $1 \& v=M 22 J V o f 4 U 39 X X t 2 E H v h o f c u Z 110 w l x w j f w N$ 0QqMQzLD1AewIWsfPcZCIBxH6Ec18. Chinese.

31. Zhang $\mathrm{Y}$, Zhou S, Wang $\mathrm{C}$. Drug resistance mechanisms and multilocus sequence typing of carbapenem-resistant Acinetobacter baumannii. Acta Universitatis Medicinalis Anhui[Internet] 2019 [cited 2020 Sep 20];2(54). Available at https://kns.cnki.net/kcms/detail/detail.aspx?FileN ame=YIKE201902032\&DbName=CJFQ2019

32. Wu H, Tan B, Zhang Z, Jiang M. [Molecular epidemiology of carbapenem-resistant Acinetobacter baumannii isolated from a hospital]. Chin J Exp Clin Infect Dis [Internet]. 2017 [cited 2020 Sep 24];11(02). Available at: https://kns.cnki.net/ $\mathrm{kcms} /$ detail/detail.aspx?dbcode=CJFD\&dbnam $\mathrm{e}=$ CJFDLAST2017\&filename $=$ ZSGR20170201 $2 \& \mathrm{v}=\% 25 \mathrm{mmd} 2 \mathrm{BHO} 2 \mathrm{kkKxIJBrljb3MTYg3m9hh}$ tKs80SOGb|9s\%25mmd2BM\%25mmd2Fmm\% 25mmd2Fhjux\%25mmd2Be4VPGC3PjIIGWZej. Chinese.

33. Li P, Niu W, Li H, Lei H, Liu W, Zhao X, et al. Rapid detection of Acinetobacter baumannii and molecular epidemiology of carbapenem-resistant A. baumannii in two comprehensive hospitals of Beijing, China. Front Microbiol [Internet]. 2015 Sep 23 [cited 2020 Sep 24];6. Available at: https://www frontiersin.org/article/10.3389/fmicb.2015.00997

34. Bado I, Papa-Ezdra R, Delgado-Blas JF, Gaudio M, Gutiérrez C, Cordeiro NF, et al. Molecular characterization of crbapenem-resistant Acinetobacter baumannii in the intensive care unit of Uruguay's University Hospital identifies the first rmtC gene in the species. Microb Drug Resist [Internet]. 2018 Sep 1 [cited 2020 Aug 13];24(7):1012-9. Available at: http://dx.doi .org/10.1089/mdr.2017.0300

35. Camargo $\mathrm{CH}$, Riberio Tiba M, Saes MR, de Vasconcellos FM, dos Santos LF, Caló Romero E, et al. Population structure analysis of carbapenemresistant Acinetobacter baumannii clinical isolates from Brazil reveals predominance of clonal complexes 1, 15, and 79. Antimicrob Agents Chemother [Internet]. 2016 Apr [cited 2020 Aug 13];60(4):2545-7. Available at: https://aac.asm .org/content/aac/60/4/2545.full.pdf

36. Rocha Araújo Castilho $S$, Silva de Miranda Godoy C, Oliveira Guilarde A, Lamaro Cardoso $\mathrm{J}$, André Porfirio MC, Junqueira-Kipnis AP, et al. Acinetobacter baumannii strains isolated from patients in intensive care units in Goiânia, Brazil: molecular and drug susceptibility profiles. PLoS One [Internet]. 2017 [cited 2020 Aug 13];12(5):e0176790. Available at: https://www ncbi.nlm.nih.gov/pmc/articles/PMC5419 $545 /$
37. Castillo Y, Nieto C, Astocondor L, Jacobs J, García C. Bacteriemia por Acinetobacter baumannii productor de oxacilinasa en hospitales de Lima, Perú. Rev Peru Med Exp Salud Publica [Internet] 2019 [cited 2020 Aug 15];36(2):364-6. Available at: http://dx.doi.org/10.17843/rpmesp.2019.362.4152. Spanish.

38. González-Villoria AM, Tamayo-Legorreta E, Garza-Ramos U, Barrios H, Sáchez-Pérez A Rodríguez-Medina N, et al. A multicenter study in Mexico finds Acinetobacter baumannii clinical isolates belonging to clonal complexes 636B (113B) and 92B harboring OXA-72, OXA-239, and OXA469. Antimicrob Agents Chemother [Internet] 2016 Mar 25 [cited 2020 Aug 13];60(4):2587-8. Available at: https://www.ncbi.nlm.nih.gov/pmc/ articles/PMC4808170/

39. Rodríguez $\mathrm{CH}$, Nastro $\mathrm{M}$, Flores $\mathrm{SA}$, Rodríguez M, Spinozzi M, Bruni G, et al. Epidemiología molecular de aislados de Acinetobacter baumannii resistentes a carbapenems en Argentina. Rev Argent Microbiol [Internet]. 2019 Jul-Sep [cited 2020 Aug 20];51(3):247-50. Available at: http://dx.doi.org/10.1016/j.ram.2017.12.004 Spanish.

40. Opazo-Capurro A, San Martín I, Quezada-Aguiluz $M$, Morales-León $F$, Domínguez-Yévenes M, Lima CA, et al. Evolutionary dynamics of carbapenem-resistant Acinetobacter baumannii circulating in Chilean hospitals. Infect Genet Evol [Internet]. 2019 [cited 2020 Sep 9];73:937. Available at: http://dx.doi.org/10.1016/j. meegid.2019.04.022

41. Ovalle MV, Saavedra SY, González MN, Hidalgo AM, Duarte C, Beltrán M. Resultados de la vigilancia nacional de la resistencia antimicrobiana de enterobacterias y bacilos Gram negativos no fermentadores en infecciones asociadas a la atención de salud, Colombia, 2012-2014. Biomédica (Bogotá) [Internet]. 2017 [cited 2020 Sep 9];37:473-85. Available at: http://www .scielo.org.co/scielo.php?script=sci_arttext\&pid =S0120-41572017000400473. Spanish.

42. Quiñones D, Carvajal I, Pérez $Y$, Hart M, Pérez J, Garcia S, et al. High prevalence of bla OXA-23 in Acinetobacter spp. and detection of bla NDM-1 in A. soli in Cuba: report from National Surveillance Program (2010-2012). New Microbes New Infections [Internet]. 2015 Sep [cited 2020 Sep 20];7:52-6. Available at: http://dx.doi .org/10.1016/j.nmni.2015.06.002

43. Rodríguez $\mathrm{CH}$, Balderrama Yarhui $\mathrm{N}$, Nastro $\mathrm{M}$, Nuñez Quezada T, Castro Cañarte G, Magne Ventura R, et al. Molecular epidemiology of carbapenem-resistant Acinetobacter baumannii in South America. J Med Microbiol [Internet]. 2016 [cited 2020 Sep 24];65(10):1088-91. Available at: http://dx.doi.org/10.1099/jmm.0.000328

44. Brisolla Tavares LC, de Vasconcellos FM, de Sousa WV, Rocchetti TT, Mondelli AL, Ferreira $A M$, et al. Emergence and persistence of high-risk clones among MDR and XDR A. baumannii at a Brazilian teaching hospital. Front Microbiol [Internet]. 2019 Jan 4 [cited 2020 Sep 20];9:2898. Available at: https://www.frontiersin .org/article/10.3389/fmicb.2018.02898

45. Levy-Blitchtein S, Roca I, Plasencia-Rebata S, Vicente-Taboada W, Velásquez-Pomar J, Muñoz L, et al. Emergence and spread of carbapenemresistant Acinetobacter baumannii international clones II and III in Lima, Peru. Emerg Microbes Infect [Internet]. 2018 Jul 4 [cited 2020 Sep 5];7:119. Available at: https://doi.org/10.1038/ s41426-018-0127-9

46. Kim UJ, Kim HK, An JH, Cho SK, Park K-H, Jang $\mathrm{H}-\mathrm{C}$. Update on the epidemiology, treatment, and outcomes of carbapenem-resistant Acinetobacter infections. Chonnam Med J [Internet]. 2014 Aug 20 [cited 2020 Oct 20];50(2):37-44. Available at: https://doi.org/10.4068/cmj.2014.50.2.37
47. Rodríguez Buenahora RD, Bustillo Zarate DE, Caicedo Sánchez DC, Cadena Sarmiento DC Castellanos Gómez C. Acinetobacter bau mannii: patógeno multirresistente emergente. MED UIS [Internet]. 2016 [cited 2020 Oct 20];29(2):113-35. Available at: http://www.scielo .org.co/scielo.php?script $=$ sci_arttext \&pid=S0121-03192016000200011\&nrm=iso. Spanish.

48. Walther-Rasmussen J, Høiby N. OXA-type carbapenemases. J Antimicrob Chemother [Internet]. 2006 Mar [cited 2020 Oct 18];57(3):373-83. Available at: https://doi.org/10.1093/jac/dki482

49. Nuñez Quezada T, Rodríguez $\mathrm{CH}$, Castro Cañarte G, Nastro M, Balderrama Yarhui N, Dabos L, et al. Outbreak of bla OXA-72-producing Acinetobacter baumannii in South America. $J$ Chemother [Internet]. 2017 [cited 2020 Aug 20];29(5):321-4. Available at: https://www.tandfonline.com/doi/ abs/10.1080/1120009X.2016.1158936

50. Georgescu M, Gheorghe I, Dudu A, Czobor I, Costache M, Cristea VC, et al. First report of OXA-72 producing Acinetobacter baumannii in Romania. New Microb New Infect [Internet]. 2016 Jul 21 [cited 2020 Oct 20];13:87-8. Available at: http://europepmc.org/abstract/MED/27547405

51. Pagano $M$, Rocha L, Sampaio JLM, Martins AF, Barth AL. Emergence of OXA-72-producing Acinetobacter baumannii belonging to high-risk clones (CC15 and CC79) in different Brazilian states. Infect Control Hospital Epidemiol [Internet]. 2017 [cited 2020 Oct 20];38(2):252-4. Available at: https://www.cambridge.org/core/ product/identifier/S0899823X16002877/type/ journal_article

52. Rodrigues-Costa F, Cayô R, Pereira Matos A, Girardello R, Martins WMBS, Carrara-Marroni FE, et al. Temporal evolution of Acinetobacter baumannii ST107 clone: conversion of blaOXA-143 into blaOXA-231 coupled with mobilization of ISAba1 upstream occAB1. Res Microbiol [Internet]. 2019 Jan-Feb [cited 2021 Jun 27];170(1):53-9. Available at: https:// www.sciencedirect.com/science/article/pii/ S0923250818301001

53. Girlich D, Damaceno QS, Oliveira AC, Nordmann P. OXA-253, a variant of the carbapenemhydrolyzing class $D \beta$-Lactamase OXA-143 in Acinetobacter baumannii. Antimicrob Agents Chemother [Internet]. 2014 May [cited 2021 Jun 28];58(5):2976-8. Available at: https://journals .asm.org/doi/abs/10.1128/AAC.02640-13

54. Sarikhani Z, Nazari R, Nateghi Rostami M. First report of OXA-143-lactamase producing Acinetobacter baumannii in Qom, Iran. Iranian J Basic Med Sci [Internet]. 2017 Nov [cited 2021 Jun 28];20(11):1282-6. Available at: https://www .ncbi.nlm.nih.gov/pmc/articles/PMC5749364/

55. Saavedra SY, Prada-Cardozo D, Verónica R, Pérez-Cardona H, Hidalgo AM, Nilse González $\mathrm{M}$, et al. Whole-genome sequence of a Colombian Acinetobacter baumannii strain, a coproducer of OXA-72 and OXA-255-like carbapenemases. Genome Announc [Internet]. 2017 Feb 16 [cited 2021 Jun 28];5(7):e01558-16. Available at: https://doi.org/10.1128/genomeA.01558-16

56. Beigverdi R, Sattari-Maraji A, Emaneini M, Jabalameli F. Status of carbapenem-resistant Acinetobacter baumannii harboring carbapenemase: first systematic review and meta-analysis from Iran. Infect Genet Evol [Internet]. 2019 Sep [cited 2021 Apr 13];73:433-43. Available at: https:// WWW sciencedirect.com/science/article/pii/ S1567134819301091

57. Alkasaby NM, El Sayed Zaki M. Molecular study of Acinetobacter baumannii isolates for metallo- $\beta$-lactamases and extended-spectrum$\beta$-lactamases genes in intensive care unit, Mansoura University Hospital, Egypt. Int J Microbiol [Internet]. 2017 [cited 2021 Apr 
13];2017:3925868. Available at: https://doi .org/10.1155/2017/3925868

58. Mesli E, Berrazeg M, Drissi M, Bekkhoucha SN, Rolain J-M. Prevalence of carbapenemaseencoding genes including New Delhi metallo$\beta$-lactamase in Acinetobacter species, Algeria. Int J Infect Dis [Internet]. 2013 Sep [cited 2021 Apr 14];17(9):e739-e43. Available at: https:// www.sciencedirect.com/science/article/pii/ S1201971213001173

59. Rodríguez $\mathrm{CH}$, Nastro M, Famiglietti A. Carbapenemases in Acinetobacter baumannii. Review of their dissemination in Latin America. Rev Argent Microbiol [Internet]. 2018 Jul-Sep [cited 2020 Oct 20];50(3):327-33. Available at: http://www.sciencedirect.com/science/article/pii/ S0325754117301785

60. Pillonetto M, Arend L, Vespero EC, Pelisson M, Chagas TPG, D'Alincourt Carvalho-Assef AP, et al. First report of NDM-1-producing Acinetobacter baumannii sequence type 25 in Brazil. Antimicrob Agents Chemother [Internet]. 2014 Dec [cited 2021 Jun 28];58(12):7592-4. Available at: https:// journals.asm.org/doi/abs/10.1128/AAC.03444-14

61. Waterman PE, McGann P, Snesrud E, Clifford RJ, Kwak YI, Munoz-Urbizo IP, et al. Bacterial peritonitis due to Acinetobacter baumannii sequence type 25 with plasmid-borne New Delhi metallo- $\beta$-lactamase in Honduras. Antimicrob Agents Chemother [Internet]. 2013 Sep [cited 2021 Jun 28];57(9):4584-6. Available at: https:// journals.asm.org/doi/abs/10.1128/AAC.00275-13

62. Cifuentes S, Moura Q, Cardoso B, Esposito F, Cerdeira L, Álvarez E, et al. Genomic features of a carbapenem-resistant OXA-219-positive Acinetobacter baumannii of international ST15 (CC15) from a patient with community-onset urinary tract infection in Chilean Patagonia. J Glob Antimicrob Resist [Internet]. 2020 Sep [cited 2021 Jun 28];22:756-8. Available at: https:/l www.sciencedirect.com/science/article/pii/ S2213716520301867

63. Bolourchi N, Azizi O, Tabrizi AMA, Esmaeili S, Fereshteh S, Badmasti F. Clonal relatedness of Acinetobacter baumannii isolated from the Middle East: a systematic review. Rev Med Microbiol [Internet]. 2020 Aug [cited 2021 Jun 29]. Available at: https://journals.Iww.com/revmedm icrobiol/Fulltext/9000/Clonal relatedness of Acinetobacter_baumannii.99747.aspx

64. Genovese C, La Fauci V, D'Amato S, Squeri A, Anzalone C, Costa GB, et al. Molecular epidemiology of antimicrobial resistant microorganisms in the 21th century: a review of the literature. Acta Biomed [Internet]. 2020 May 11 [cited 2021 Jun 29];91(2):256-73. Available at: https://www.ncbi .nlm.nih.gov/pmc/articles/PMC7569612/

65. Grisold AJ, Luxner J, Bedenić B, Diab-Elschahawi $M$, Berktold $M$, Wechsler-Fördös $A$, et al. Diversity of oxacillinases and sequence types in carbapenem-resistant Acinetobacter baumannii from Austria. Int J Environ Res Public Health [Internet]. 2021 [cited 2021 Jun 29];18(4):2171. Available at: https://www.mdpi.com/1660-4601/ $18 / 4 / 2171$

66. Gu Y, Jiang $Y$, Zhang $W, Y u$ Y, He X, Tao J, et al. Risk factors and outcomes of blood- stream infections caused by Acinetobacter baumannii: a case-control study. Diagnostic microbiology and infectious disease. Diagn Microbiol Infect Dis [Internet]. 2021 Feb [cited 2021 Jun 29];99(2):115229. Available at: https:// www.sciencedirect.com/science/article/pii/ S0732889320306064

67. Jun SH, Lee DE, Hwang HR, Kim N, Kim HJ, Lee $\mathrm{YC}$, et al. Clonal change of carbapenem-resistant Acinetobacter baumannii isolates in a Korean hospital. Infect Genet Evol [Internet]. 2021 Sep [cited 2021 Jun 29];93:104935. Available at: https://www.sciencedirect.com/science/article/ pii/S156713482100232X

68. Meijie J, Li L, Liu S, Zhang Z, Li N, Zhao S. Extensively drug resistant Acinetobacter baumannii ST369 infection in emergency intensive care unit in Shandong Province, China. Res Square [Internet]. 2020 Jan 31 [cited 2020 Nov 10]. Available at: http://europepmc.org/abstract/ PPR/PPR126539

69. López-Durán PA, Fonseca-Coronado S, LozanoTrenado LM, Araujo-Betanzos S, Rugerio-Trujillo DA, Vaughan G, et al. Nosocomial transmission of extensively drug resistant Acinetobacter baumannii strains in a tertiary level hospital. PLoS One [Internet]. 2020 Apr 17 [cited 2020 Nov 10];15(4):e0231829. Available at: https://doi .org/10.1371/journal.pone.0231829

70. Khurshid M, Rasool MH, Ashfaq UA, Aslam $B$, Waseem $M, X u Q$, et al. Dissemination of blaOXA-23-harbouring carbapenem-resistant Acinetobacter baumannii clones in Pakistan. J Glob Antimicrob Resist [Internet]. 2020 Jun [cited 2021 Jun 30];21:357-62. Available at: https://www.sciencedirect.com/science/article/ pii/S2213716520300023

71. Khuntayaporn P, Kanathum P, Houngsaitong J, Montakantikul P, Thirapanmethee K, Chomnawang MT. Predominance of international clone 2 multidrug-resistant Acinetobacter baumannii clinical isolates in Thailand: a nationwide study. Ann Clin Microbiol Antimicrob [Internet]. 2021 Mar 20 [cited 2021 Jun 30];20(19). Available at: https:// doi.org/10.1186/s12941-021-00424-z

72. Shirazi AS, Shafiei M, Solgi H, Aslani MM, Azizi O, Badmasti F. Different virulence capabilities and ompA expressions in ST2 and ST513 of multidrug-resistant Acinetobacter baumannii. Curr Microbiol [Internet]. 2019 Jun [cited 2021 Jun 30];76(6):723-31. Available at: https://doi .org/10.1007/s00284-019-01686-9

73. Matsui $M$, Suzuki $M$, Suzuki $M$, Yatsuyanagi J, Watahiki M, Hiraki Y, et al. Distribution and molecular characterization of Acinetobacter baumannii international clone II lineage in Japan. Antimicrob Agents Chemother [Internet]. 2018 Jan 25 [cited 2021 Jun 30];62(2):e02190-17. Available at: https://journals.asm.org/doi/abs/10.1128/ AAC.02190-17

74. Kostyanev T, Xavier BB, García-Castillo M, Lammens C, Bravo-Ferrer Acosta J, Rodríguez-Baño $\mathrm{J}$, et al. Phenotypic and molecular characterizations of carbapenem-resistant Acinetobacter baumannii isolates collected within the EURECA study. Int J Antimicrob Agents [Internet]. 2021 Jun [cited 2021 Jun 30];57(6):106345. Avail- able at: https://www.sciencedirect.com/science/ article/pii/S092485792100087X

75. Nawfal Dagher T, Al-Bayssari C, Chabou S, Antar N, Diene SM, Azar E, et al. Investigation of multidrug-resistant ST2 Acinetobacter baumannii isolated from Saint George hospital in Lebanon. BMC Microbiol [Internet]. 2019 Feb 2 [cited $2021 \mathrm{Jul}$ 2];19(1):29. Available at: https:// doi.org/10.1186/s12866-019-1401-2

76. Rezaei A, Fazeli H, Faghri J. Investigation of carbapenem resistant Acinetobacter baumannii ST2 in Iran. Acta Microbiol Immunol Hung [Internet]. 2021 May 13 [cited 2021 Jun 29];68(1):20-6. Available at: https://akjournals.com/view/jour nals/030/68/1/article-p20.xml

\section{THE AUTHORS}

Haiyang Yu, physician specializing in preventive medicine and public health with a master's degree in public health. Nosocomial Infection Management Department, Chongqing University Three Gorges Hospital, Chongqing, China. Healthcare-Associate Infections National Laboratory, Pedro Kourí Tropical Medicine Institute (IPK), Havana, Cuba. https://orcid.org/0000 $-0002-8690-7070$

Guillermo Ezpeleta-Lobato, physician with dual specialties in microbiology \& parasitology and preventive medicine \& public health, with a master's degree in public health. Head of the International Travelers' Health Department, Bizkaia International Vaccination Center, Bilbao, Spain. https://orcid.org/0000-0003-0970-6352

Xu Han, physician specializing in preventive medicine and public health, with a master's degree in public health. Epidemiology Department, IPK. Havana, Cuba. https://orcid .org/0000-0003-2343-1818

Yenisel Carmona-Cartaya, physician specializing in microbiology with a master's degree in bacteriology and mycology. Healthcare-Associate Infections National Laboratory, IPK. Havana, Cuba. https://orcid.org/0000-0003-1241-5302

Dianelys Quiñones-Pérez (corresponding author: dia@ipk.sld.cu), physician specializing in microbiology, with a master's degree in bacteriology and mycology, and a doctorate in medical sciences. Healthcare-Associate Infections NationalLaboratory,IPK,Havana,Cuba.https://orcid .org/0000-0003-4506-6890

Submitted: February 2, 2021

Approved for publication: November 16, 2021 Disclosures: None 